\title{
Epitope Structure of the Carbohydrate Recognition Domain of Asialoglycoprotein Receptor to a Monoclonal Antibody Revealed by High-Resolution Proteolytic Excision Mass Spectrometry
}

\author{
Raluca Stefanescu, ${ }^{1}$ Rita Born, ${ }^{2}$ Adrian Moise, ${ }^{1}$ Beat Ernst, ${ }^{2}$ Michael Przybylski ${ }^{1}$ \\ ${ }^{1}$ Laboratory of Analytical Chemistry and Biopolymer Structure Analysis, Department of Chemistry, University of Konstanz, \\ 78457 Konstanz, Germany \\ ${ }^{2}$ Department of Molecular Pharmacy, Pharmacenter, University of Basel, 4056 Basel, Switzerland
}

\begin{abstract}
Recent studies suggest that the $\mathrm{H} 1$ subunit of the carbohydrate recognition domain (H1CRD) of the asialoglycoprotein receptor is used as an entry site into hepatocytes by hepatitis $A$ and $B$ viruses and Marburg virus. Thus, molecules binding specifically to the CRD might exert inhibition towards these diseases by blocking the virus entry site. We report here the identification of the epitope structure of $\mathrm{H} 1 \mathrm{CRD}$ to a monoclonal antibody by proteolytic epitope excision of the immune complex and highresolution MALDI-FTICR mass spectrometry. As a prerequisite of the epitope determination, the primary structure of the H1CRD antigen was characterised by ESI-FTICR-MS of the intact protein and by LC-MS/MS of tryptic digest mixtures. Molecular mass determination and proteolytic fragments provided the identification of two intramolecular disulfide bridges (seven Cys residues), and a Cys-mercaptoethanol adduct formed by treatment with $\beta$-mercaptoethanol during protein extraction. The H1CRD antigen binds to the monoclonal antibody in both native and Cys-alkylated form. For identification of the epitope, the antibody was immobilized on N-hydroxysuccinimide (NHS)-activated Sepharose. Epitope excision and epitope extraction with trypsin and FTICR-MS of affinity-bound peptides provided the identification of two specific epitope peptides (5-16) and (17-23) that showed high affinity to the antibody. Affinity studies of the synthetic epitope peptides revealed independent binding of each peptide to the antibody.
\end{abstract}

Key words: Asialoglycoprotein receptor, H1CRD protein, Epitope structure, Proteolytic epitope excision, High-resolution mass spectrometry

Abbreviations: FTICR-MS, Fourier transform ion cyclotron resonance mass spectrometry; MALDI, matrix-assisted laser desorption/ionization; CRD, carbohydrate recognition domain; IAA, iodoacetamide; SPPS, solid-phase peptide synthesis; DMF, dimethylformamide; NHS, $N$-hydroxysuccinimide; PyBOP, (benzotriazol-1-yloxy)trispyrrolidinophosphonium hexafluorophosphate

Electronic supplementary material The online version of this article (doi:10.1007/s13361-010-0010-y) contains supplementary material, which is available to authorized users.

Correspondence to: Michael Przybylski; e-mail: Michael.Przybylski@unikonstanz.de

\section{Introduction}

The asialoglycoprotein receptor (ASGP-R) belongs to the 1 C-type (calcium-dependent) class of lectins [1] and is located on hepatocytes of all mammalian organisms [2]. The 
receptor is a hetero-oligomer consisting of various ratios of the two homologous subunits $\mathrm{H} 1$ and $\mathrm{H} 2$, which exhibit $58 \%$ sequence homology [3]. Both subunits are composed of a cytosolic N-terminal domain, a single transmembrane segment, a stalk domain and a C-terminal carbohydrate recognition domain (CRD) (Figure 1a). The carbohydrate recognition domain of subunit H1 (H1CRD) binds glycoproteins with terminal galactose (Gal) and $N$-acetylgalactosamine (GalNAc) motifs [4, 5]. The receptor provides clearance of circulating ligand glycoproteins by receptormediated endocytosis followed by degradation in the lysosome, and it is then recycled to the cell surface. Although both subunits are required for endocytosis of ligands, the carbohydrate binding activity was shown to be associated predominantly with $\mathrm{H} 1$ [6]. Recent studies suggest that ASGP-R is used as an entry site into hepatocytes by hepatitis B virus, Marburg virus and hepatitis A virus $[7,8]$. Thus, molecules that bind specifically to the carbohydrate recognition domain (CRD) might exert inhibitory effects towards these diseases by blocking the virus entry site. Knowledge of the epitope(s) of antibodies against H1CRD may contribute to the development of specific agents capable of blocking carbohydrate binding.

H1CRD consists of the amino acid residues (147-290) of full-length H1. The X-ray crystal structure of H1CRD (available at the PDB accession number, 1dv8) has been described for the amino acid residues 153-280, although the structures at the N- and C-terminal sequences (147-152) and (281-290) were not identified as a result of thermal disorder [9]. According to the structural data, H1CRD is a globular protein comprising six $\beta$ strands $(\beta 1-\beta 6)$ and two $\alpha$ helices of 10 and 11 residues, respectively (Figure $1 b$ ). The protein contains seven cysteine residues for which two disulfide bridges have been described and a third disulfide bond proposed from the X-ray structure, and three $\mathrm{Ca}^{2+}$ binding sites. The carbohydrate binding site comprises the amino acid residues Gln-239, Asp-241, Trp-243, Glu-252, Asp-253 and Asn-264 [10-12]. Although the carbohydrate binding site resides within residues 239-264, the complete amino acid sequence of the globular CRD structure is required as an immunogen for antibody production.

In the present study we have identified the epitope structure of a recombinant H1CRD antigen expressed in $E$. coli $[13]$ to a specific monoclonal antibody, using proteolytic excision of the H1CRD immune complex and affinity mass spectrometry. As a basis for the epitope identification, the complete primary structure and intramolecular disulfide bridges of H1CRD were characterised by high-resolution FTICR mass spectrometry and LC-MS/MS. Affinity mass spectrometry approaches using proteolytic epitope excision and epitope extraction have been previously described in detail and applied in epitope identifications [14-19]. In the general analytical method [14-17, 19], the immobilised ligand-binder (antigen-antibody) complex is subjected to limited proteolytic digestion, followed by mass spectrometric

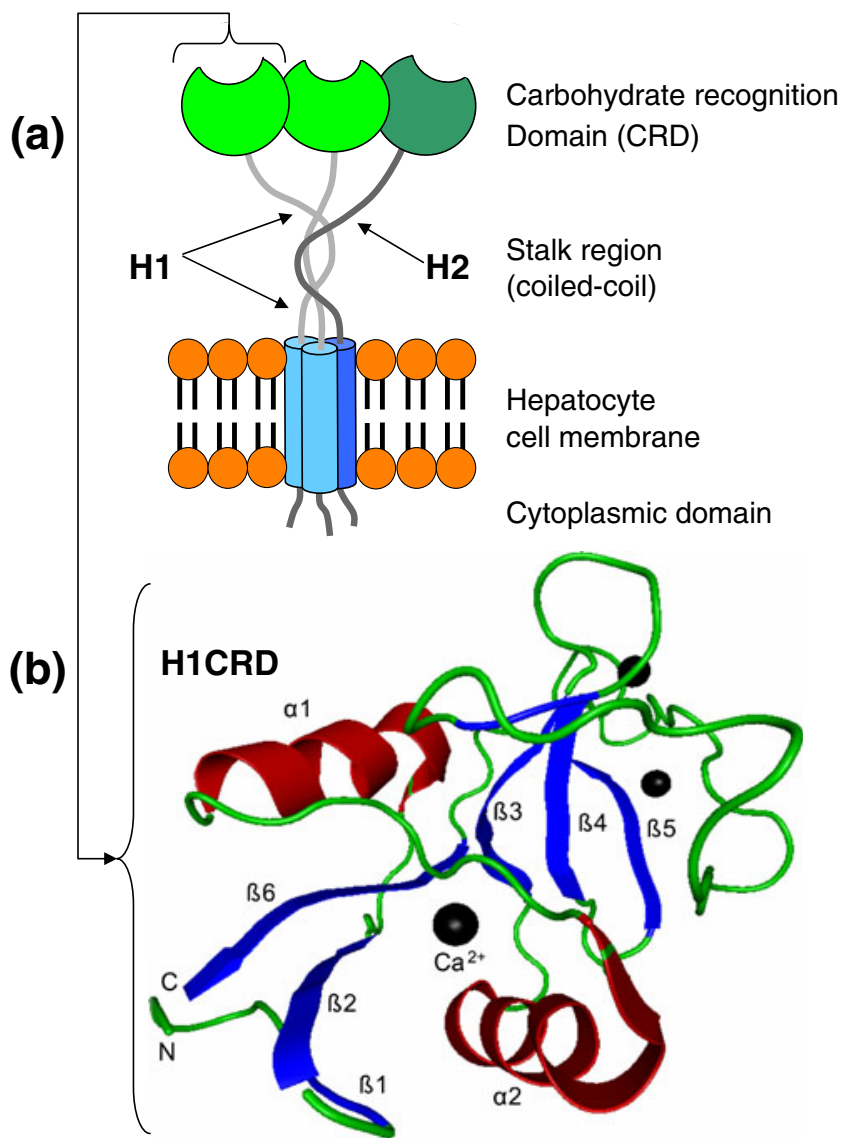

Figure 1. (a) Schematic representation of the asialoglycoprotein receptor (ASGPR), illustrating the hetero-oligomer composed of one $\mathrm{H} 1$ and one $\mathrm{H} 2$ subunit, and the four domains of the $\mathrm{H} 1$ subunit; cytosolic, transmembrane, stalk and carbohydrate recognition domains are indicated by arrows. (b) Ribbon diagram of the X-ray crystal structure of H1CRD (PDB accession number, 1dv8). The $\mathrm{N}$ - and $\mathrm{C}-$ terminus are shown on the left side. $\alpha$ Helices are indicated by red arrows and $\beta$ strands by blue arrows; calcium ions are indicated by black dots. (Figure prepared using the program BallView 1.1.1.)

analysis of the eluted affinity-bound epitope peptide fragment (s). In the proteolytic step, the epitope is protected from digestion owing to the shielding of the ligand-binder interaction structure; hence, epitope excision on an immobilised immune complex is essential for isolation, specific dissociation and identification of the bound epitope. In a variation of this approach ("epitope extraction") the antigen ligand is first subjected to proteolytic digestion, and the mixture of peptide fragments is subsequently presented to the binder (antibody) [19]. In alternative approaches [20-22], epitope identifications have been performed by proteolytic digestion in solution without immobilisation of the antigen-antibody complex, by utilizing the specific signal depletion of the complex preserved on the MALDI target. Here we show that the application of both epitope excision MS and epitope extraction MS provided the identification of a specific epitope structure at the N- 
terminal part of H1CRD, which is independent and remote from the carbohydrate binding site. In contrast to the binding of carbohydrates to H1CRD that requires the presence of calcium ions, antibody binding and epitope were found to be identical with and without the presence of calcium. Moreover, we show that the two synthesized N-terminal epitope peptides each exhibit independent affinity to the antibody. The determination of the epitope structure provides a molecular basis for approaches towards the development of specific inhibitors of the carbohydrate binding of $\mathrm{H} 1$.

\section{Experimental}

\section{Preparation of HICRD}

The recombinant carbohydrate recognition domain of $\mathrm{H} 1$ (H1CRD) was expressed in E. coli and purified by affinity chromatography and size exclusion chromatography as previously described $[5,23]$. The cDNA comprised the amino acid residues 147-290 of the H1 subunit of ASGPR and an initiator methionine (see sequence numbering of the recombinant H1CRD in the Supplementary Figure 1). Nterminal Edman sequence determination of the purified recombinant H1CRD, performed with a Procise-470 automated Edman sequencer (Applied Biosystems, Foster City, $\mathrm{CA}$ ), showed the lack of the initiator methionine.

\section{Reduction and Alkylation of Disulfide Bonds}

Disulfide bridge reduction was performed by addition of a 50-fold molar excess of dithiothreitol (DTT) per cysteine residue followed by incubation at $56^{\circ} \mathrm{C}$ for $1 \mathrm{~h}$. The sample was then alkylated by incubation for $1 \mathrm{~h}$ at $25^{\circ} \mathrm{C}$ in the dark with a 2.5 -fold molar excess of iodoacetamide (IAA) over DTT. Carboxymethylation was also carried out without prior cysteine reduction in order to modify only cysteine residues not involved in disulfide bridges.

\section{Antibody Immobilization}

The monoclonal antibody clone B01.4 [23] was dissolved in $0.2 \mathrm{M} \mathrm{NaHCO}_{3}$ and $0.5 \mathrm{M} \mathrm{NaCl}$ coupling buffer ( $\mathrm{pH} 8.3$ ) to a final concentration of $0.5 \mu \mathrm{g} \mu \mathrm{L}^{-1}$. A $200 \mu \mathrm{L}$ aliquot of this solution was added to $66 \mathrm{mg}$ dry NHS-activated 6aminohexanoic acid-coupled Sepharose (Sigma, St. Louis, MO) and the coupling reaction performed for $1 \mathrm{~h}$ at $20^{\circ} \mathrm{C}$. The coupling product was loaded into a $0.8 \mathrm{~mL}$ microcolumn (Mobitec, Göttingen, FRG) and washed sequentially with blocking ( $0.1 \mathrm{M}$ aminoethanol, $0.5 \mathrm{M} \mathrm{NaCl}, \mathrm{pH} 8.3$ ) and washing solution $\left(0.2 \mathrm{M} \mathrm{CH}_{3} \mathrm{COONa} 0.5 \mathrm{M} \mathrm{NaCl}\right.$, pH 4.0). Each washing step was performed with $24 \mathrm{~mL}$ (four times $6 \mathrm{~mL}$ ) buffer and the procedure was repeated after $1 \mathrm{~h}$ incubation in blocking buffer.

\section{Proteolytic Epitope Excision and Extraction}

For epitope excision $50 \mu \mathrm{g}$ solutions of H1CRD dissolved in $200 \mu \mathrm{L}$ PBS ( $5 \mathrm{mM} \mathrm{Na}_{2} \mathrm{HPO}_{4}, 150 \mathrm{mM} \mathrm{NaCl}, \mathrm{pH}$ 7.5) with and without the addition of $20 \mathrm{mM} \mathrm{CaCl} 2$ were applied to the affinity matrix. The column was gently shaken for $2 \mathrm{~h}$ to allow complete antigen binding, and unbound material was removed by washing with $10 \mathrm{~mL}$ PBS. Remaining affinitybound antigen was digested for $2 \mathrm{~h}$ at $37^{\circ} \mathrm{C}$ with $1 \mu \mathrm{g}$ tosyl phenylalanyl chloromethyl ketone (TPCK)-treated trypsin in $50 \mathrm{mM} \mathrm{NH} \mathrm{HCO}_{3}$, or for $20 \mathrm{~h}$ with endoprotease Glu-C. Supernatant non-epitope containing peptides were removed by washing with $50 \mathrm{~mL}$ PBS. The immune complex was then dissociated by addition of $0.5 \mathrm{~mL} 0.1 \%$ trifluoroacetic acid (TFA), $\mathrm{pH} \sim 2$. The column was gently shaken for $15 \mathrm{~min}$ at $20{ }^{\circ} \mathrm{C}$ and the released epitope peptides collected in an Eppendorf cup for mass spectrometric analysis (Supplementary Figure 4). The column was regenerated by washing with $10 \mathrm{~mL} 0.1 \%$ TFA acid, $\mathrm{pH} \sim 2$, followed by $20 \mathrm{~mL}$ PBS. Epitope extraction was performed in the same manner by applying the proteolytic peptide mixture directly to the column. Desalting and concentration of the sample were performed by using ZipTip C18 pipette tips as previously described [24].

\section{Peptide Synthesis}

Epitope peptides were synthesized by solid-phase peptide synthesis (SPPS) according to the Fmoc/tBu strategy using a semiautomated peptide synthesizer EPS 221 (Abimed, Langenfeld, Germany). All syntheses were performed on a NovaSyn TGR resin using $N(\alpha)$-fluorenylmethyloxycarbonyl (Fmoc)-protected amino acids in a fivefold molar excess relative to the amount of resin. Deprotection of the $N$ $(\alpha)$-amino group was carried out by addition of $2 \% 1,8$ diazabicyclo[5.4.0] undec-7-ene (DBU) and 2\% piperidine in dimethylformamide (DMF). Activation was performed in 0.9 M (benzotriazol-1-yloxy)trispyrrolidinophosphonium hexafluorophosphate (PyBOP) and $4 \mathrm{M} \mathrm{N}$-methylmorpholine base (NMM) in DMF. Cleavage of peptides from the resin was performed for $2-3 \mathrm{~h}$ at $20{ }^{\circ} \mathrm{C}$ using a solution containing $95 \%$ TFA, $2.5 \%$ triethylsilane and $2.5 \%$ deionized water.

Preparative reversed-phase high-performance liquid chromatography (RP-HPLC) purification of synthetic epitope peptides was carried out on a Knauer HPLC system (Knauer, Bad Homburg, Germany) using a preparative C18 column GROM-SIL 120 ODS-4 SE with $10 \mu \mathrm{m}$ silica, $250 \times 20 \mathrm{~mm}$, $120 \AA$ A pore size (Grom, Herrenberg-Kayh, Germany). HPLC chromatograms were recorded by UV detection at $220 \mathrm{~nm}$.

\section{Mass Spectrometry}

MALDI-FTICR mass spectrometry was performed with a Bruker APEX II FTICR mass spectrometer equipped with a 7 T magnet (Bruker Daltonik, Bremen, Germany) using an 
external Scout 100 MALDI ion source with fully automated $\mathrm{X}-\mathrm{Y}$ target stage with pulsed collision gas $[25,26]$. The pulsed nitrogen laser was operated at $337 \mathrm{~nm}$ and MALDIgenerated ions cooled with the pulsing collision gas and directly captured into the hexapole ion guide. Ions generated by 20-30 laser shots were accumulated in the hexapole for $0.5-1 \mathrm{~s}$ at $30 \mathrm{~V}$ and extracted at $15 \mathrm{~V}$. The matrix solution was prepared by dissolving $100 \mathrm{mg}$ of 2,5-dihydroxybenzoic acid (DHB) in $1 \mathrm{~mL}$ acetonitrile $/ 0.1 \%$ TFA in water $(2: 1 \mathrm{v} / \mathrm{v})$. A $0.5 \mu \mathrm{L}$ aliquot of matrix solution was deposited on the MALDI target, mixed with $0.5 \mu \mathrm{L}$ of sample solution and allowed to dry in ambient air. Mass spectra were obtained by using 10 laser shots for each scan and accumulating 32-64 scans. External calibration was performed by using the monoisotopic masses of singly protonated ions of human angiotensin I and II, bradykinin, neurotensin, bovine insulin $\beta$ chain (oxidized) and bovine insulin.

ESI-FTICR- MS was performed with the Bruker APEX II FTICR mass spectrometer equipped with an APOLLO ESI source as previously described [19]. The sample was dissolved in a solution containing $50 \%$ methanol, $48 \%$ water and $2 \%$ acetic acid, and introduced at $2 \mu \mathrm{L} \mathrm{min}{ }^{-1}$ through a PEEK capillary to the spraying needle using a syringe pump. A voltage of $-4200 \mathrm{~V}$ was applied between the metal-coated entry of the glass capillary and the grounded spray needle.
The voltage applied at the end cap was $-3800 \mathrm{~V}$. Nitrogen was employed as nebulizing gas to stabilise the spray, and desolvation was facilitated by using $\mathrm{N}_{2}$ drying gas at $150{ }^{\circ} \mathrm{C}$. Before each measurement cycle, the source and the analyser cell were quenched for $50 \mathrm{~ms}$. The ESI ions were passed through the glass capillary and from the capillary exit through the skimmer entering into the hexapole ion guide. The declustering potential $(\triangle \mathrm{CS})$ between capillary exit and skimmer was $60 \mathrm{~V}$. After a predefined accumulation time in the hexapole (0.1-2 s) the voltage of the extraction plate was reversed and ions were extracted for transmission to the ICR cell. External calibration was carried out using monoisotopic masses of angiotensin I fragment ions formed by in-source fragmentation; typical calibration mass accuracy was $0.5 \mathrm{ppm}$ at a resolving power of approximately 80,000.

LC/MS analysis was performed with an Agilent (Waldbronn, Germany) HP1100 liquid chromatograph for binary gradient elution (model G1312A) coupled to a Bruker Daltonik Esquire 3000+ ion trap mass spectrometer. A binary gradient system consisting of solvent A $(0.1 \%$ aqueous formic acid) and solvent B (80\% acetonitrile, $0.1 \%$ aqueous formic acid) was employed for LC separation; the sample was dissolved in solvent $\mathrm{A}$ at an injection volume of $5 \mu \mathrm{L}$. A $150 \mathrm{~mm} \times 4.6 \mathrm{~mm} \times 3 \mu \mathrm{m}$ Discovery RP- 18 column was used for peptide separation. All LC-MS data

(a)
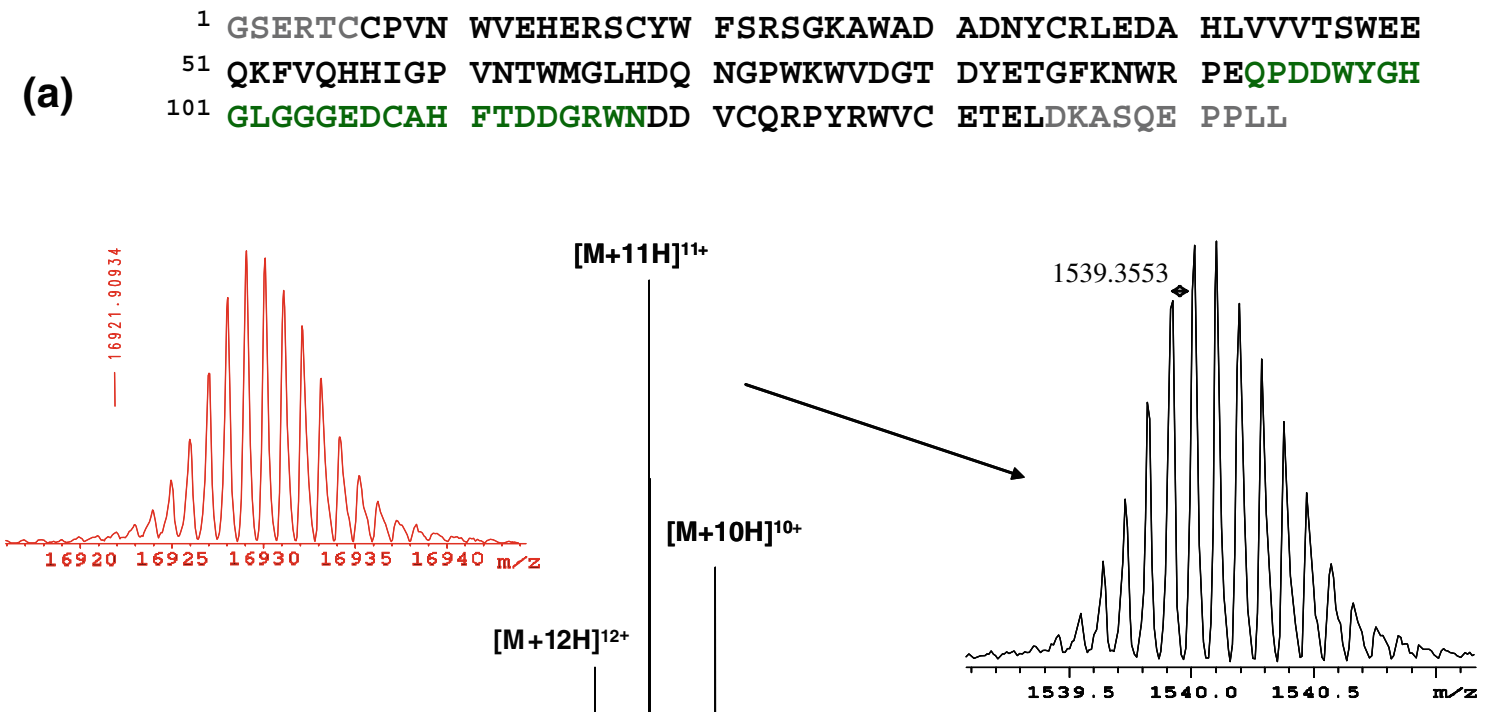

(b)

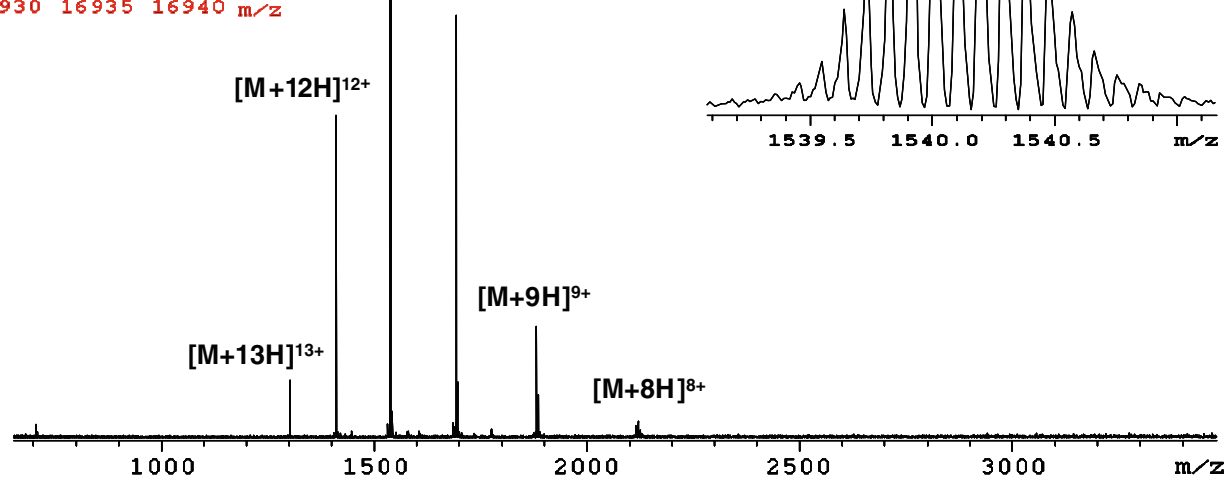

Figure 2. (a) Amino acid sequence of recombinant H1CRD; (b) ESI-FTICR mass spectrum of H1CRD in $50 \%$ methanol and $1 \%$ aqueous acetic acid at a concentration of $6 \mathrm{pmol} \mathrm{LL}^{-1}$, showing the $8+$ to $13+$ charged molecular ions. The isotope resolution of the $11+$ charged molecular ion is shown in the upper right panel. The isotopic structure of the $[\mathrm{M}+\mathrm{H}]^{+}$ion after deconvolution is shown on the left side 
Table 1. Comparison of monoisotopic molecular masses of recombinant H1-CRD determined by ESI-FTICR-MS and the calculated masses containing different numbers of disulfide linkages and modifications

\begin{tabular}{cccc}
\hline Number of disulfide bonds & \multicolumn{2}{c}{ Monoisotopic molecular weight $[\mathrm{M}+\mathrm{H}]^{+}$} \\
\cline { 2 - 4 } & H1-CRD & - Met & - Met/+ $\beta$-ME \\
\hline Reduced state & 16981.6263 & 16850.5858 & 16926.5841 \\
1 S-S bond & 16979.6107 & 16848.5702 & 16924.5685 \\
2 S-S bonds & 16977.5951 & 16846.5546 & 16922.5529 \\
3 S-S bonds & 16975.5795 & 16844.5390 & 16920.5373 \\
\hline
\end{tabular}

were obtained in the positive ion mode. Mass spectra were recorded in the full scan mode $(\mathrm{m} / \mathrm{z} 200-1500)$. Ion source parameters were $20 \mathrm{psi}$ nebulizer gas and $10.0 \mathrm{~L} \mathrm{~min}^{-1}$ drying gas with a temperature of $300{ }^{\circ} \mathrm{C}$. MS/MS experiments were carried out in the autofragmentation mode.

\section{Results and Discussion}

\section{Characterisation of Primary Structure and Disulfide Linkages of HICRD}

The H1CRD of the receptor protein was expressed in E. coli and purified by affinity chromatography and size exclusion chromatography as previously described [23]. Amino acid residues in the sequence of the recombinant H1CRD were numbered 1-144 as shown in Figure 2a and Supplementary Figure 1, and this sequence numbering is used throughout.

As a precondition for the identification of the epitope, the primary structure and disulfide linkages of H1CRD were initially characterised by ESI-FTICR-MS of the intact protein and LC-MS/MS of proteolytic digest mixtures. The molecular mass determination of H1CRD was performed (Figure 2b) using an aliquot of the stock solution diluted to a final concentration of $6 \mu \mathrm{M}$. The determined experimental mass of $16,921.9093$ is well in agreement with the calculated mass of the protein of $16,922.5529$, without methionine, containing two disulfide bridges, two reduced cysteine residues and one cysteine- $\beta$-mercaptoethanol (Cys$\beta$-ME) adduct (Table 1). The lack of the initiator methionine, a frequently observed modification of recombinant proteins [27], was confirmed by N-terminal Edman sequence analysis yielding $\mathrm{NH}_{2}$-GSERTCCP- (data not shown) and by LCMS/MS (Supplementary Table 2; Supplementary Figures 3, 4). The Cys- $\beta$-ME adduct was formed during extraction of the protein from the cell lysate and purification in the presence of $\beta$ ME [23].

The primary structure was further characterised by digestion of native and alkylated H1CRD with trypsin and LysC protease followed by MALDI-FTICR-MS and LCMS/MS of the proteolytic fragments. MALDI-FTICR mass spectra of the tryptic digest of native and alkylated H1CRD are shown in Figure $3 \mathrm{~b}-\mathrm{d}$ and the identified peptides summarised in Table 2 and Supplementary Table 1. Twelve tryptic fragments (T1-T12) are formed by complete digestion of H1CRD (Figure 3a), all of which were identified with the exception of the small peptides T1 and T4 (Table 2). The MALDI-FTICR mass spectra of the tryptic peptide mixture of native H1CRD revealed the fragments T5 and T11, thereby allowing the presence of the disulfide bridge Cys35-Cys-130 to be established. In addition, the accurate mass of $\mathrm{T} 2\left([\mathrm{M}+\mathrm{H}]^{+}, m / z\right.$ 1470.615) was 2.02 lower than the calculated mass with reduced Cys- 6 and Cys-7 residues, thus corresponding to a vicinal disulfide bridge (Cys-6-Cys7). The identification of the vicinal disulfide bridge in the fragment $\mathrm{T} 2$ was ascertained by reduction and carbamidomethylation of cysteine residues and MALDI-FTICR-MS (Figure 3d). The alkylated tryptic peptides each contained a single alkylated cysteine residue (T3, Cys-18; T10, Cys-122; T11, Cys-130), whereas the fragment T2 contained two alkylated cysteine residues (Cys-6, Cys-7), thus confirming the vicinal disulfide bridge Cys-6-Cys-7 of H1CRD (Supplementary Table 1). Additional confirmation was obtained

Table 2. Molecular masses and amino acid sequences of tryptic peptide fragments of native H1-CRD determined by MALDI-FTICR-MS

\begin{tabular}{|c|c|c|c|c|c|}
\hline$[\mathrm{M}+\mathrm{H}]_{\exp }^{+}$ & {$[\mathrm{M}+\mathrm{H}]_{\mathrm{calc}}^{+}$} & $\Delta m(\mathrm{ppm})$ & Tryptic fragment & Cysteine residue & Sequence \\
\hline 948.409 & 948.4033 & 6.0 & $\mathrm{~T} 3$ & $\mathrm{C} 18$ & ${ }^{17} \mathrm{SCYWFSR}^{23}$ \\
\hline 1122.511 & 1122.5136 & 2.3 & T11 & $\mathrm{C} 130$ & ${ }^{128}{ }^{12 V C E T E L D K ~}{ }^{136}$ \\
\hline 1184.480 & 1184.4789 & 0.9 & T5 & $\mathrm{C} 35$ & ${ }^{27} \mathrm{AWADADNYCR}{ }^{36}$ \\
\hline 1417.619 & 1417.6270 & 6 & $\mathrm{~T} 8$ & & ${ }^{76}$ WVDGTDYETGFK $^{87}$ \\
\hline 1451.679 & 1451.6485 & 21 & T10 & $\mathrm{C} 122$ & ${ }^{117} \mathrm{WNDDVCQRPYR}^{127}$ \\
\hline 1470.615 & 1470.6253 & 7.0 & T2 disulfide bridge $^{\mathrm{a}}$ & $\mathrm{C} 6 / \mathrm{C} 7$ & ${ }^{5}$ TCCPVNWVEHER $^{16}$ \\
\hline 1883.001 & 1882.9545 & 24.6 & T6 & & ${ }^{37}$ LEDAHLVVVTSWEEQK $^{52}$ \\
\hline 2303.980 & 2303.9694 & 4.6 & $\begin{array}{l}\text { T5/T11 } \\
\text { disulfide bridge }\end{array}$ & $\mathrm{C} 35 / \mathrm{C} 130$ & $\begin{array}{l}{ }^{27} \text { AWADADNYCR }^{36} \\
{ }^{128} \text { WVCETELDK }^{136}\end{array}$ \\
\hline 2698.298 & 2698.3096 & 4.3 & $\mathrm{~T} 7$ & & ${ }^{53} \mathrm{FVQHHIGPVNTWMGLHDQNGPWK}{ }^{75}$ \\
\hline 3287.319 & 3287.3620 & 13.0 & T9 & $\mathrm{C} 108$ & ${ }^{88}$ NWRPEQPDDWYGHGLGGGEDCAHFTDDGR $^{116}$ \\
\hline
\end{tabular}

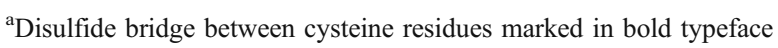


(a)

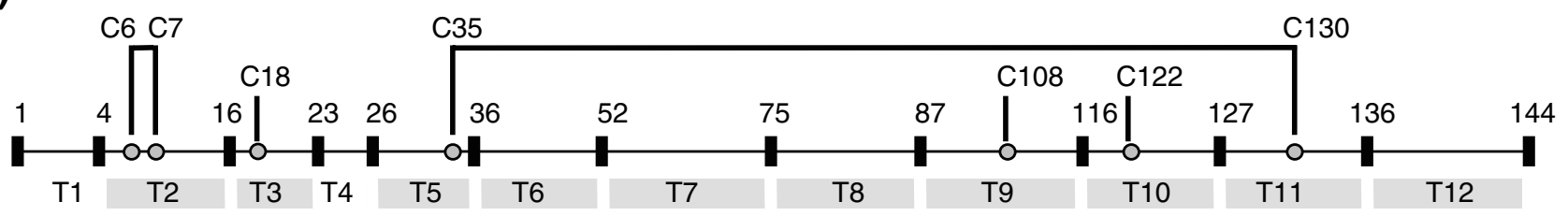

(b)

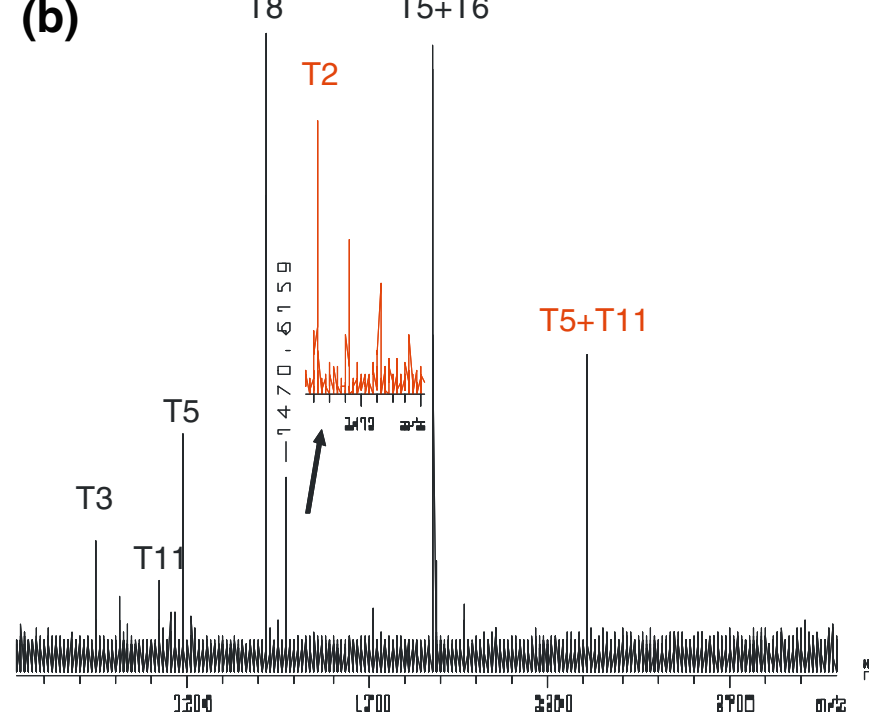

(c)

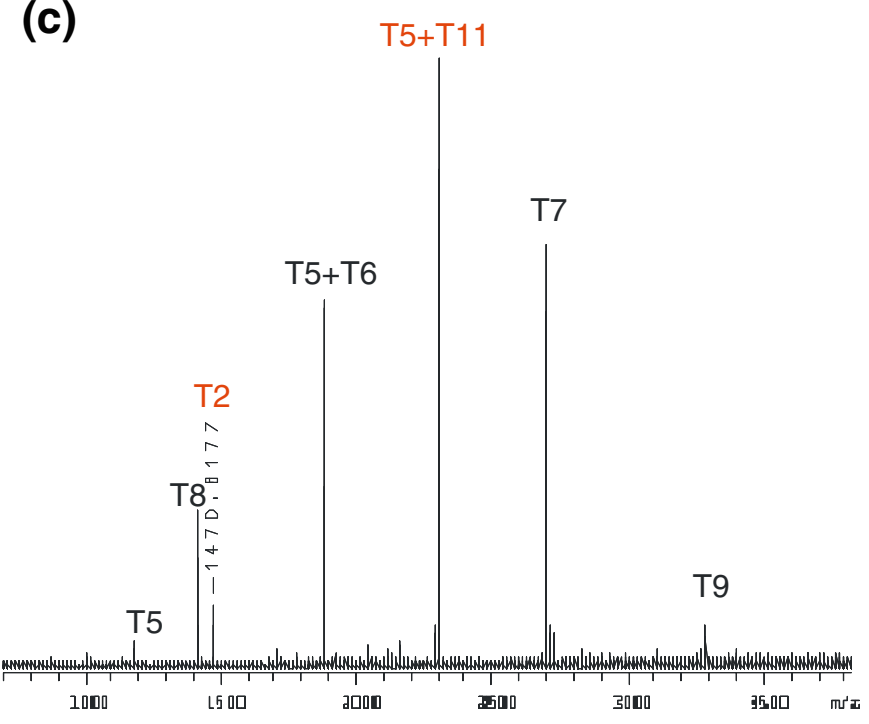

(d)

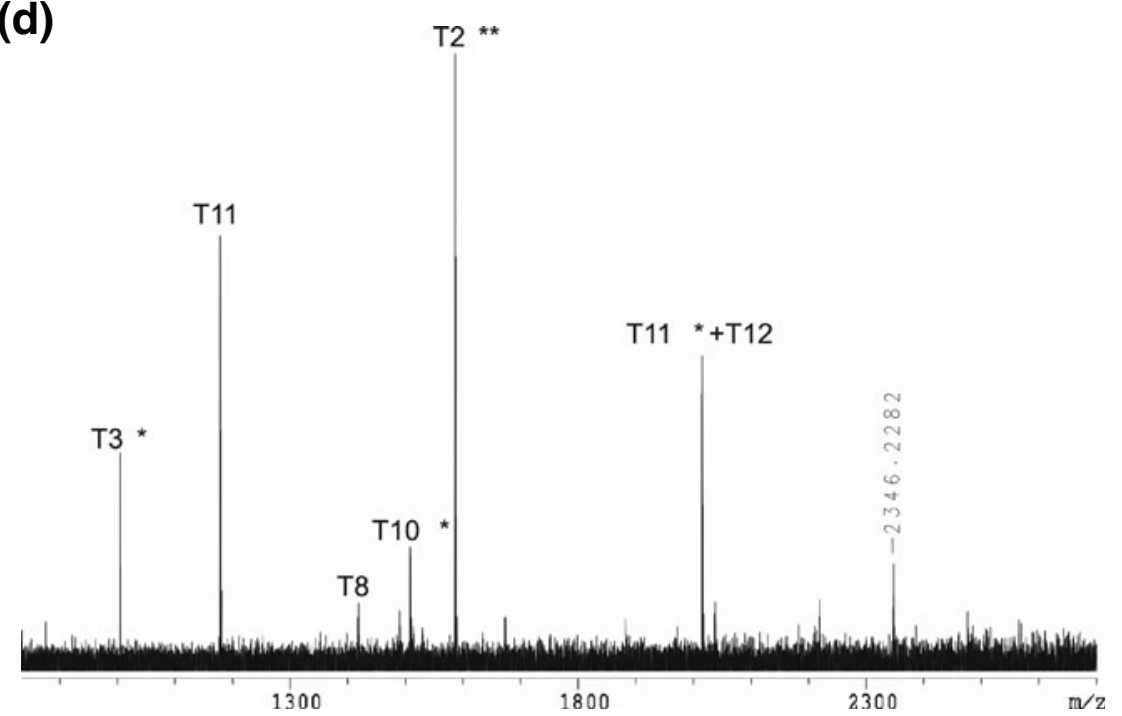

Figure 3. (a) Schematic representation of tryptic cleavage sites and peptide fragments, and location of cysteine residues and disulfide bonds identified in the recombinant H1CRD. Tryptic fragments identified by mass spectrometry are shown by grey bars. The two disulfide bridges identified are indicated by connector lines between the cysteine residues involved. (b, c) MALDIFTICR mass spectra of the peptide mixture obtained by tryptic digestion of native $\mathrm{H} 1 \mathrm{CRD}\left(5 \mathrm{~h}, 37^{\circ} \mathrm{C}, 1: 50\right.$ enzyme to substrate ratio). Fragments containing a disulfide bridge are indicated in red. The spectra were recorded by adjusting the hexapole parameters for optimum sensitivity of the mass range selected: (b) time-of-flight delay $2500 \mu \mathrm{s}$, RF amplitude 2.5; (c) time-offlight delay 3500 Ms, RF amplitude 3.5. (d) MALDI-FTICR-MS of the tryptic peptide mixture of reduced and alkylated H1CRD; carbamidomethyl modification of cysteine residues are indicated by asterisks

by LC-MS/MS upon LysC digestion of the reduced and alkylated H1CRD (Supplementary Table 2). The identification of the disulfide bridge Cys-35-Cys-130 is in agreement with the X-ray structure [9], although the Cys-6-Cys-7 linkage was not found by X-ray crystallography. The formation of a disulfide bond between adjacent cysteine residues is a relatively rare structural element, which is usually associated with a $\beta$-turn of the protein backbone; 
(a)

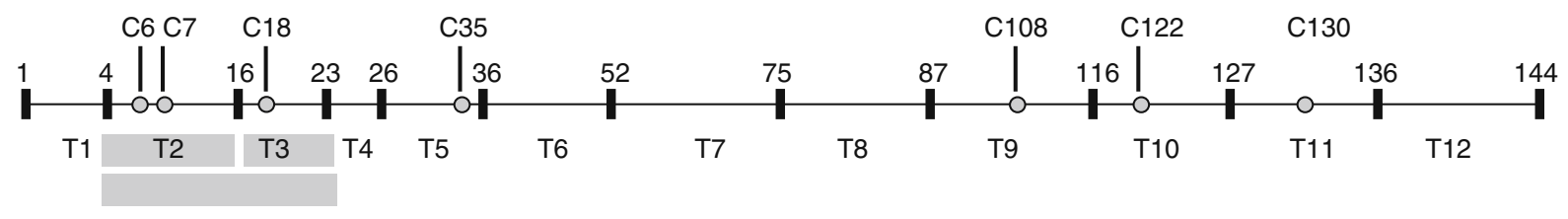

(b) ${ }_{\text {Т }}$

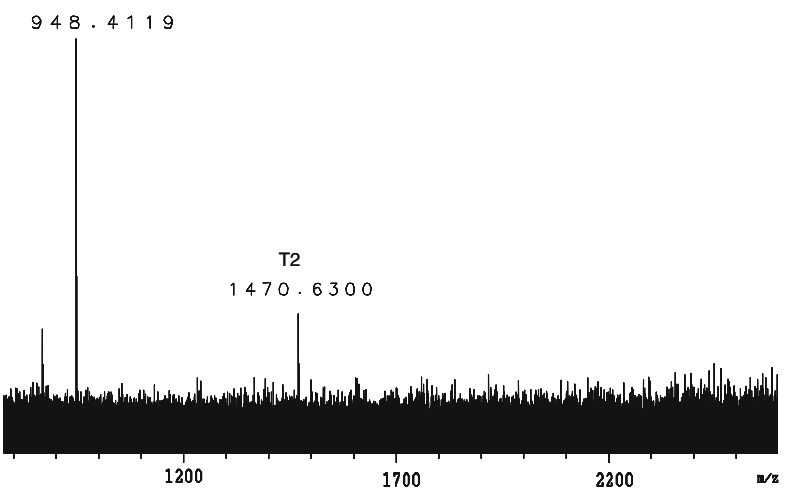

(c) ${ }_{\mathrm{T}^{*}}$

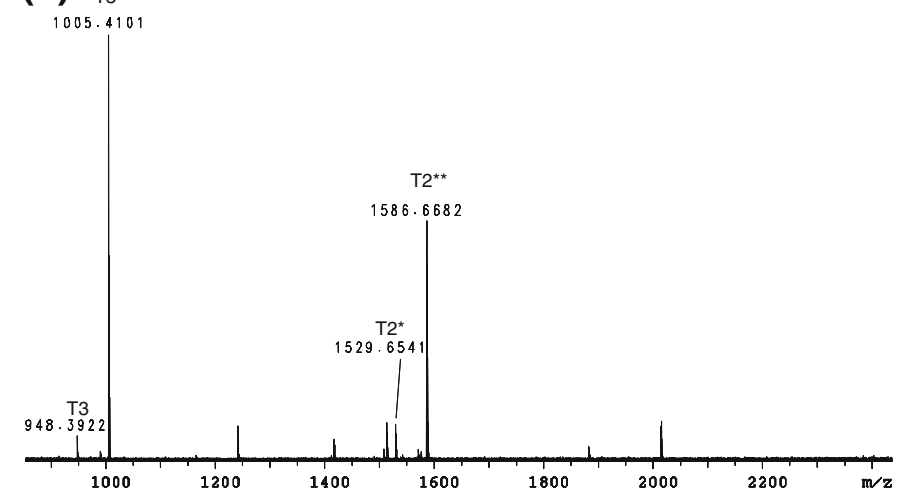

(d)

$\mathrm{T} 3$
948.4065

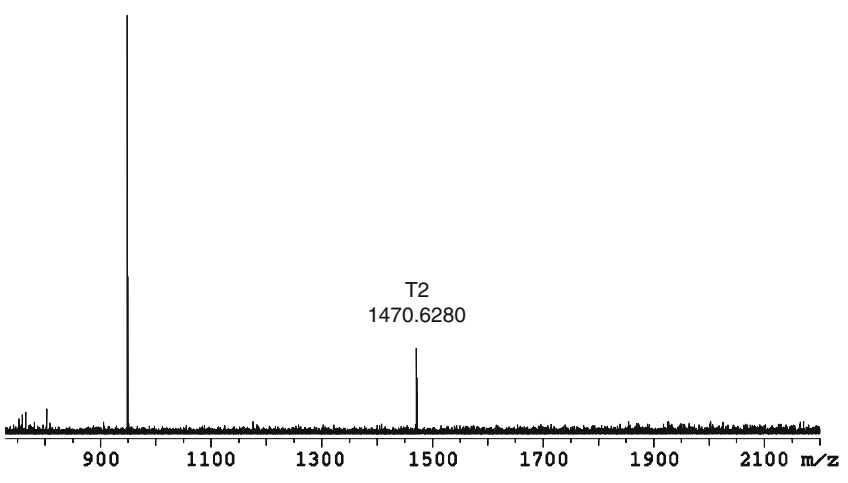

Figure 4. (a) Location of the antibody epitope of H1CRD shown by grey bars; (b) MALDI-FTICR-MS of the tryptic epitope peptides obtained by epitope excision MS of the immune complex with native $\mathrm{H}_{1 \mathrm{CRD}}$ without the presence of $\mathrm{CaCl}_{2}$; (c) MALDI-FTICR-MS of tryptic epitope peptides after epitope extraction MS of alkylated H1CRD; (d) MALDI-FTICR-MS of tryptic epitope peptides by epitope excision MS of the immune complex in the presence of $20 \mathrm{mM} \mathrm{CaCl}_{2}$

vicinal disulfide linkages, however, have been identified and structurally characterised in a number of proteins including enzymes, receptors and toxins [28-30]. Under the conditions of the MS analyses, no disulfide scrambling was observed; the $\beta$-ME mixed disulfide adduct is labile under the moderately acidic solution conditions used and was not found.

\section{Epitope Structure Identification of a Monoclonal Antibody to HICRD}

On the basis of the primary structure characterisation, proteolytic epitope excision and extraction mass spectrometry were applied to the identification of the epitope recognised by the monoclonal antibody (B01) against H1CRD. Proteolytic excision MS analyses were carried out both with the native H1CRD and the reduced/alkylated antigen, with two identical sets of experiments with and without the presence of calcium ions (Figure 4b, c). After preparation of the affinity column with the immobilised antibody, epitope excision was carried out with the antibody-bound H1CRD as described in the "Experimental". Following digestion with trypsin the supernatant containing unbound peptide fragments was removed, the column washed extensively with buffer under binding conditions, and affinity- bound peptides were eluted under acidic conditions.

The FTICR mass spectra of the affinity-bound epitope peptide fraction provided the identification of two tryptic peptides, ${ }^{5}$ TCCPVNWVEHER ${ }^{16}$ (T2) containing the vicinal Cys-6-Cys-7 disulfide linkage, and ${ }^{17}$ SCYWFSR $^{23}$ (T3) (Figure 4a, b). These peptides identified the location of the epitope at the N-terminal domain within residues 5-23 of H1CRD. To investigate the possible role of the Cys- 6 and 


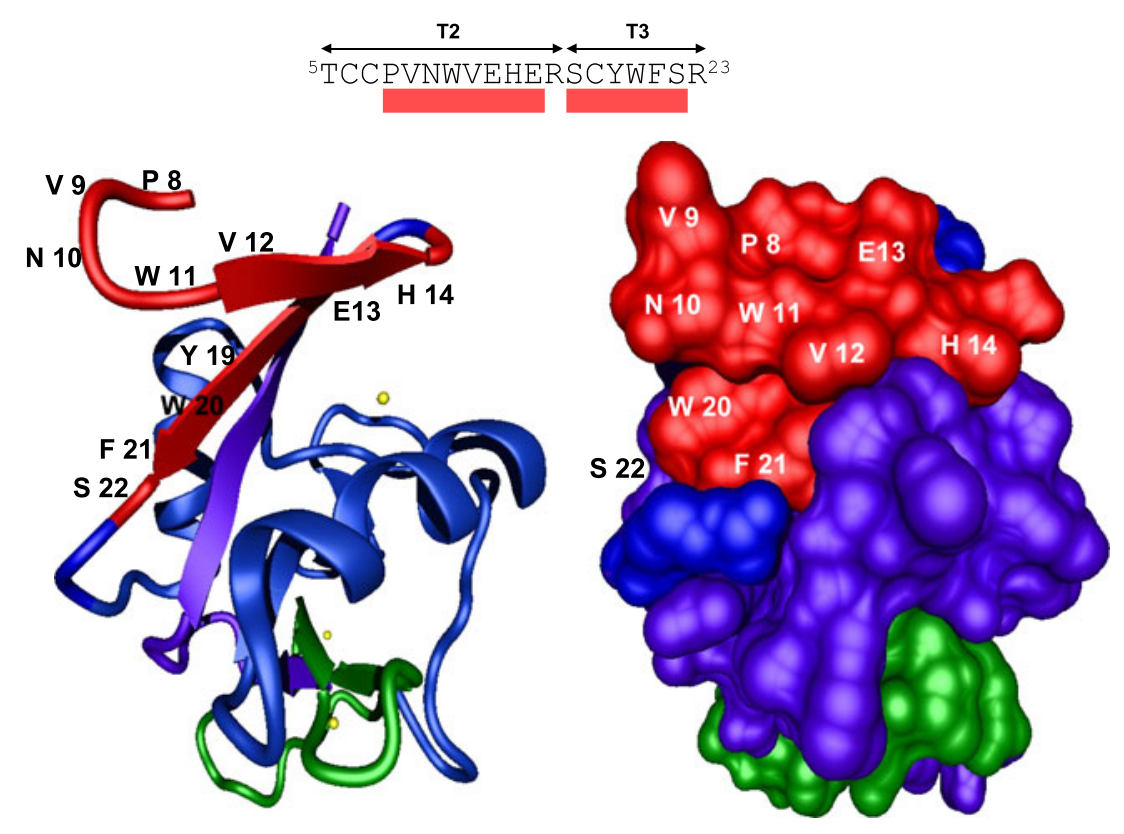

Figure 5. Structure model of H1CRD (ribbon diagram), and accessible surface area of the epitope identified by the tryptic fragments T3 and T2. The identified epitope sequences are depicted in red, the carbohydrate binding site is shown in green and the position of calcium ions in yellow. Structure models were prepared with the BallView v1.1.1. programme and are based on the X-ray crystal structure of H1CRD (PDB entry 1DV8)

Cys-7 residues in the interaction with the antibody, epitope excision MS was additionally performed with the alkylated H1CRD and this led to the identification of the same epitope peptides, T2 and T3. Moreover, epitope extraction mass spectrometry, by subjecting a $50 \mu \mathrm{g}$ aliquot of the mixture of tryptic peptides of the alkylated H1CRD to the affinity column, provided the identical N-terminal fragments $\mathrm{T} 2$ and T3 (Figure 4c), consistent with the previous results; this suggested that the Cys-6 and Cys-7 residues, albeit contained in the isolated epitope peptide T2, are not involved in the binding interaction.

Epitope excision MS performed with and without the presence of calcium ions provided the identification of identical epitope peptides, T2 and T3 (Figure 4b and c), a result which is consistent with the binding site of the antibody being remote from the carbohydrate binding. The differences in abundances of the two affinity-eluted epitope peptides were also identical to those found with the epitope identification without the presence of calcium; the different abundances may be due to differences in relative hydrophobicities of the peptides as is frequently observed in MALDI-MS, and/or differences in relative binding affinities of the two peptides. The proteolytic formation and identification of the peptide $\mathrm{T} 2$ showed that the Arg-16 residue is not shielded by the antibody binding, and suggested that Arg-16 is not involved in the epitope interaction.

A structure model based on the crystal structure of H1CRD suggests that the amino acid residues of peptide $\mathrm{T} 2$ are accessible at the protein surface (Figure 5); however, surface accessibilities from crystal structure data of the antibody-immune complex are not available. The amino acid residues Thr-5 and Cys-6 have not been described in the $\mathrm{X}$-ray structure [9]. The position of Arg-16 together with Glu-15 within the loop connecting the $\beta 1$ strand ${ }^{12} \mathrm{VEH}^{14}$ and the $\beta 2$ strand ${ }^{17} \mathrm{SCYWF}^{21}$ appears to favour the tryptic cleavage observed at Arg-16. The first three residues of the peptide T3 adjacent to Arg-16, Ser-17, Cys-18 and Tyr-19 are not accessible whereas the last four amino acids ${ }^{20} \mathrm{WFSR}^{23}$ are exposed. Considering the tryptic cleavage sites and the location of Cys residues, the epitope comprising the peptides T2 and T3 may be formally described by the two partial sequences ${ }^{8} \mathrm{PVNWVEH}{ }^{14}$ and ${ }^{19} \mathrm{YWFS}^{22}$.

\section{Affinity of Synthetic Epitope Peptides to the Antibody}

On the basis of the identification of the epitope structure, the characterisation of the binding affinity of the peptides $\mathrm{T} 2$ and T3 was a further aim of this study. The peptides T2 and T3 were synthesised as described in the "Experimental", with the cysteine residues protected by acetamidomethylation in order to prevent the formation of disulfide bridges following deprotection and purification. The interaction of the synthetic peptides with the immobilised antibody was characterised by affinity mass spectrometry. Binding of a mixture of the two peptides to the antibody and MALDIFTICR-MS of the affinity elution fraction provided the recovery and identification of both peptides $\mathrm{T} 2$ and $\mathrm{T} 3$, consistent with the results of the epitope extraction MS (Supplementary Figure 2). Moreover, the affinity binding and elution of each individual peptide and MALDI-FTICR- 
MS analysis confirmed that each peptide was binding independently to the antibody (data not shown).

\section{Conclusions}

Proteolytic epitope excision and extraction mass spectrometry of an antibody complex of the H1 subunit of the carbohydrate recognition domain of the asialoglycoprotein receptor H1CRD provide the identification of the epitope comprising the $\mathrm{N}$-terminal domain ${ }^{5} \mathrm{~T}-\mathrm{R}^{23}$, with proteolytic accessibility observed at the R-16 and R-23 residues. The primary structure characterisation and identification of disulfide linkages of H1CRD was found to be an essential prerequisite for the identification of the antibody epitope. The epitope recognised by the antibody is located on the opposite side of the carbohydrate binding site comprising the sequence ${ }^{239} \mathrm{Gln}-\mathrm{Asn}^{264}$, consistent with the lack of a neutralising effect of the antibody on carbohydrate binding; moreover, the epitope binding by the antibody was ascertained to be independent from the presence of calcium ions. These results confirm the feasibility of the B01 antibody as a molecular tool for the isolation and functional characterisation of carbohydrate complexes of H1CRD [5]. Furthermore, proteolytic epitope excision mass spectrometry is shown here as a highly efficient approach to reveal molecular details of antigen-antibody interactions.

\section{Acknowledgements}

This study was partially supported by the Deutsche Forschungsgemeinschaft (Bonn, Germany; PR-175-14-1), the Roche Research Foundation (Grant for R. Born) and by the University of Konstanz.

\section{References}

1. Drickamer, K.: Two distinct classes of carbohydrate-recognition domains in animal lectins. J. Biol. Chem. 263, 9557-9560 (1988)

2. Stockert, R.J.: The asialoglycoprotein receptor: relationships between structure, function, and expression. Physiol. Rev. 75, 591-609 (1995)

3. Spiess, M., Lodish, H.F.: Sequence of a second human asialoglycoprotein receptor: conservation of two receptor genes during evolution. Proc. Natl. Acad. Sci. U.S.A. 82, 6465-6469 (1985)

4. Halberg, D.F., Wager, R.E., Farrell, D.C., Hildreth, J.T., Quesenberry, M.S., Loeb, J.A., Holland, E.C., Drickamer, K.: Major and minor forms of the rat liver asialoglycoprotein receptor are independent galactose-binding proteins. Primary structure and glycosylation heterogeneity of minor receptor forms. J. Biol. Chem. 262, 9828-9838 (1987)

5. Khorev, O., Stokmaier, D., Schwardt, O., Cutting, B., Ernst, B.: Trivalent, Gal/GalNAc-containing ligands designed for the asialoglycoprotein receptor. Bioorg. Med. Chem. 16, 5216-5231 (2008)

6. Shia, M.A., Lodish, H.F.: The two subunits of the human asialoglycoprotein receptor have different fates when expressed alone in fibroblasts. Proc. Natl. Acad. Sci. U.S.A. 86, 1158-1162 (1989)
7. Dotzauer, A., Gebhardt, U., Bieback, K., Gottke, U., Kracke, A., Mages, J., Lemon, S.M., Vallbracht, A.: Hepatitis A virus-specific immunoglobulin A mediates infection of hepatocytes with hepatitis A virus via the asialoglycoprotein receptor. J. Virol. 74, 10950-10957 (2000)

8. Treichel, U., Meyer zum Buschenfelde, K.H., Stockert, R.J., Poralla, T., Gerken, G.: The asialoglycoprotein receptor mediates hepatic binding and uptake of natural hepatitis B virus particles derived from viraemic carriers. J. Gen. Virol. 75(Pt 11), 3021-3029 (1994)

9. Meier, M., Bider, M.D., Malashkevich, V.N., Spiess, M., Burkhard, P.: Crystal structure of the carbohydrate recognition domain of the H1 subunit of the asialoglycoprotein receptor. J. Mol. Biol. 300, 857-865 (2000)

10. Kolatkar, A.R., Leung, A.K., Isecke, R., Brossmer, R., Drickamer, K., Weis, W.I.: Mechanism of N-acetylgalactosamine binding to a C-type animal lectin carbohydrate-recognition domain. J. Biol. Chem. 273, 19502-19508 (1998)

11. Kolatkar, A.R., Weis, W.I.: Structural basis of galactose recognition by C-type animal lectins. J. Biol. Chem. 271, 6679-6685 (1996)

12. Seimetz, D., Frei, E., Schnolzer, M., Kempf, T., Wiessler, M.: One step isolation of bovine asialoglycoprotein receptor and its characterization by sequence analysis and MALDI mass spectrometry. Biosci. Rep. 19, 115-124 (1999)

13. Stokmaier, D., Khorev, O., Cutting, B., Born, R., Ricklin, D., Ernst, T.O., Boni, F., Schwingruber, K., Gentner, M., Wittwer, M., Spreafico, M., Vedani, A., Rabbani, S., Schwardt, O., Ernst, B.: Design, synthesis and evaluation of monovalent ligands for the asialoglycoprotein receptor (ASGP-R). Bioorg. Med. Chem. 17, 7254-7264 (2009)

14. Suckau, D., Kohl, J., Karwath, G., Schneider, K., Casaretto, M., BitterSuermann, D., Przybylski, M.: Molecular epitope identification by limited proteolysis of an immobilized antigen-antibody complex and mass spectrometric peptide mapping. Proc. Natl. Acad. Sci. U.S.A. 87, 9848-9852 (1990)

15. Papac, D.I., Hoyes, J., Tomer, K.B.: Epitope mapping of the gastrinreleasing peptide/anti-bombesin monoclonal antibody complex by proteolysis followed by matrix-assisted laser desorption ionization mass spectrometry. Protein Sci. 3, 1485-1492 (1994)

16. Glocker, M.O., Nock, S., Sprinzl, M., Przybylski, M.: Characterization of surface topology and binding area in complexes of the elongation factor proteins EF-Ts and EF-Tu GDP from Thermus thermophilus. A study by protein-chemical modification and mass spectrometry. Chemistry 4, 707-715 (1998)

17. Fiedler, W., Borchers, C., Macht, M., Deininger, S.O., Przybylski, M.: Molecular characterization of a conformational epitope of hen egg white lysozyme by differential chemical modification of immune complexes and mass spectrometric peptide mapping. Bioconjug. Chem. 9, 236-241 (1998)

18. Macht, M., Marquardt, A., Deininger, S.O., Damoc, E., Kohlmann, M., Przybylski, M.: "Affinity-proteomics": direct protein identification from biological material using mass spectrometric epitope mapping. Anal. Bioanal. Chem. 378, 1102-1111 (2004)

19. Stefanescu, R., Iacob, R.E., Damoc, E.N., Marquardt, A., Amstalden, E., Manea, M., Perdivara, I., Maftei, M., Paraschiv, G., Przybylski, M.: Mass spectrometric approaches for elucidation of antigenantibody recognition structures in molecular immunology. Eur. J. Mass Spectrom. 13, 69-75 (2007)

20. Kiselar, J.G., Downard, K.M.: Direct identification of protein epitopes by mass spectrometry without immobilization of antibody and isolation of antibody-peptide complexes. Anal. Chem. 71, 17921801 (1999)

21. Morrissey, B., Downard, K.M.: Kinetics of antigen-antibody interactions employing a MALDI mass spectrometry immunoassay. Anal. Chem. 80, 7720-7726 (2008)

22. Zhao, Y., Muir, T.W., Kent, S.B., Tischer, E., Scardina, J.M., Chait, B. T.: Mapping protein-protein interactions by affinity-directed mass spectrometry. Proc. Natl. Acad. Sci. U.S.A. 93, 4020-4024 (1996)

23. Born, R.: dissertation, University of Basel; Born, R.; Stokmaier, D.; Rabbani, R.; Ernst, B. 2009; unpublished results (2008)

24. Kussmann, M., Lassing, U., Sturmer, C.A., Przybylski, M., Roepstorff, P.: Matrix-assisted laser desorption/ionization mass spectrometric peptide mapping of the neural cell adhesion protein neurolin purified by sodium dodecyl sulfate polyacrylamide gel electrophoresis or acidic precipitation. J. Mass Spectrom. 32, 483493 (1997) 
25. Baykut, G., Jertz, R., Witt, M.: Matrix-assisted laser desorption/ ionization Fourier transform ion cyclotron resonance mass spectrometry with pulsed in-source collision gas and in-source ion accumulation. Rapid Commun. Mass Spectrom. 14, 1238-1247 (2000)

26. Witt, M., Fuchser, J., Baykut, G.: Fourier transform ion cyclotron resonance mass spectrometry with NanoLC/microelectrospray ionization and matrixassisted laser desorption/ionization: analytical performance in peptide mass fingerprint analysis. J. Am. Soc. Mass Spectrom. 14, 553-561 (2003)

27. Frottin, F., Martinez, A., Peynot, P., Mitra, S., Holz, R.C., Giglione, C., Meinnel, T.: The proteomics of N-terminal methionine cleavage. Mol. Cell. Proteomics 5, 2336-2349 (2006)
28. Carugo, O., Cemazar, M., Zahariev, S., Hudaky, I., Gaspari, Z., Perczel, A., Pongor, S.: Vicinal disulfide turns. Protein Eng. 16, 637-639 (2003)

29. Cemazar, M., Zahariev, S., Lopez, J.J., Carugo, O., Jones, J.A., Hore, P. J., Pongor, S.: Oxidative folding intermediates with nonnative disulfide bridges between adjacent cysteine residues. Proc. Natl. Acad. Sci. U.S. A. 100, 5754-5759 (2003)

30. Wang, X., Connor, M., Smith, R., Maciejewski, M.W., Howden, M.E., Nicholson, G.M., Christie, M.J., King, G.F.: Discovery and characterization of a family of insecticidal neurotoxins with a rare vicinal disulfide bridge. Nat. Struct. Biol. 7, 505-513 (2000) 